\title{
VAIKŲ INDIVIDUALIZUOTO UGDYMO PEDAGOGINĖS REKONSTRUKCIJOS: DISKURSAI IR METAKONTEKSTAI
}

\author{
Audronė Juodaityte் \\ Šiauliu universitetas
}

\begin{abstract}
Anotacija
Straipsnyje atskleidžiamos pagrindinès vaikų tarpusavio sąveikos rūšys ir („Aš“”, „Tu“, „Mes“) reikšmès, atsirandančios natūralioje aplinkoje, bei pedagoginių rekonstrukcijų, jas atitinkančių ir jų neatitinkančių, pobūdis. Taikant konvencialumo ir korespondencijos metodą, orientuojamasi i respektyvaus ugdymo ideją, ginančią vaiko, kaip asmens ir individo, teisę ugdymo procese išlikti unikaliu. Parodoma, kaip pedagogas gali ịprasminti šią vaikų galimybę nuolat komunikuodamas su vaiko pasauliu, interpretuodamas ugdymą sugestyvaus egalitarizmo idejų pagrindu ir realizuodamas ji kaip vaikų bei suaugusiujų dialogą.

PAGRINDINIAI ŽODŽIAI: vaikų individualizavimas, diskursai, metakontekstas.
\end{abstract}

\begin{abstract}
The article discloses main types of children's interaction ("I", "You", "We") and its meanings, emerging in natural environment as well as the type of pedagogical reconstructions, corresponding or not corresponding to these meanings. Using the method of conventionality and correspondence, it is orientated to the idea of respective education, defending the right of the child as a person and individual to remain unique in education. It is demonstrated how the educator can give a sense to this children's opportunity, constantly communicating with the children's world, interpreting education on the basis of suggestive egalitarianism ideas and implementing it as a child-adult dialogue.

KEYWORDS: children's individualism, discourses, metacontext.
\end{abstract}

\section{Ivadas}

Beveik visa XX amžiaus pedagogika grindžiama vulgarios nelygybès arba iškreiptos vaiku lygybes sampratomis, kuriu pagrindą sudaro skiriamasis požiūris i vaikus kaip , ¡ $\mathfrak{i}$ kitokius“. Šiuo pagrindu ugdymo procesuose įtvirtinama nelygybė.

Šiuolaikinis individualizuotas vaikų ugdymas grindžiamas vaikų lygybės samprata ir sugestyvaus egalitarizmo teze, tai radikaliai keičia tradicini ugdyma, jame isivyravusi skirtingų ir individualių vaikų nuvertinima, prioritetus nepagristai suteikiant vienoms savybėms, o kitas - nepagristai nuvertinant. Tai lemia perèjima prie ugdymo, kuriame individualūs vaikų skirtumai ir jų išskirtinumas yra kaip ugdymo vertybès.

Palankią situaciją plètotis egalitarizmui ugdyme sudaro demokratijos vertybiu isitvirtinimas (Hansen, Kaufmann, Seifer, 1997): pagarba individualiems vaiku skirtumams, sąlygų sudarymas jų raiškai, saviaktualizacijai, dialogams (kultūriniams, socialiniams ir kt.). I. Fetscher (1983), G. Feuser (1982) teigimu, vaiku lygybès samprata būtent ir išreiškia demokratijos vertybes ugdyme, kartu savo tu- 
riniu atkreipia dėmesị i nepalankią vaikų individualybės raiškos situaciją. Ugdyme dažnai išemiliminuojamos vaikų individualios savybės arba jos priešpriešinamos kitų vaikų savybėms. Teigiama (Caldwell, 1990; Freire, 1997), kad ugdyme tiek individualūs vaikų panašumai, tiek ir skirtumai negali būti analizuojami kaip ugdymo alternatyvos.

Tačiau pedagogams individualizuojant ugdymą reikia naujo požiūrio i̇ vaikų individualumo, išskirtinumo raišką ugdymo procesuose, išmokti pažinti vaiką kaip individa, konstruojantị savaji patyrimą. Todẻl kyla mokslinė problema: kaip, kokiais būdais ir kur pedagogas gali igyti naujos patirties, susiformuoti naują sampratą, būtiną vaikų ugdymui individualizuoti, ir kaip šią patirti jis galètų rekonstruoti?

Straipsnio tikslas: atskleisti šiuolaikinio vaiku individualizuoto ugdymo pedagoginių rekonstrukcijų diskursą ir metakontekstus, būtinus vaikų išskirtinumo (individualumo) raiškos suvokimui.

Straipsnio objektas: individualizuoto ugdymo pedagoginès rekonstrukcijos.

Metodai: teorinès literatūros analizè, metaanalizè, kontentanalizè.

Metodologinès nuostatos. Šiuolaikinis pedagoginis žinojimas interpretuojamas kaip judejjimas nuo teorijos ị praktiką, nuo apibendrintų tiesų - i konkrečias, praktines. Kartu jis apibūdinamas kaip mėginimas ịveikti grynojo mąstymo (objektines) tiesas ir siekti subjektyviojo prado, individualios sąveikos su vaikų pasauliu. Šiomis sąlygomis atrastos tiesos susiejamos su egzistuojančiu pedagoginiu požiūriu i̇ vaikų gyvenimo situacijų neapibrěžtumą, lokalizavimąsi ir monumentualizavimąsi. Naujų, pedagoginių nuostatų i vaikų ugdymą kaita ịvyksta ne tik sąveikaujant socialine aplinka, kaip realybe, bet ir su vaiko vidiniu pasauliu, kaip natūra, ir su jo kuriama aplinka, kaip subkultūra.

Pasitelkiami kritinès refleksijos metodologija pagristi diskursai, kai žinios gaunamos ne per predikaciją (ivardijamą predikatą), bet per referenciją, kai grižtama i tikrovès reikšmes ir vertes, o teiginiai priklauso nuo prezumpozicijos (situaciniu, kontekstualių veiksnių), kurių pagrindu nustatomas kritinis, refleksyvusis pedagoginio mąstymo modalumas.

Vaikų pasaulio, kaip jų pačių sukurtos socialinès, subkultūrinės erdvės, reikšmès atskleidžiamos per kontekstualuji situacini pedagoginio pobūdžio polilogą su vaikų pasaulio vertybėmis, issigilinant i iji refleksijos pagrindu ir atliekant konstruktyvistinio pobūdžio, pedagogines įžvalgas. Ieškoma pedagoginių pažiūrų modifikavimo galimybių, nuolat plètojant pedagogo sąveiką su vaikų pasaulio reikšmèmis. Tai padeda surasti idejų vaikų ugdymo projekcijai, orientuotai į interpersonalinę pedagogo sąveiką su vaiku. 
Išryškinamos svarbiausios idejjos, integruojančios pedagogo neopedocentristines pažiūras į ugdymo projektą, kuris pagrịstas idejja: vaikų pasaulis yra tarsi suaugusiuju pasaulio dalis, taigi vaikai turi teisę kaip ir suaugusieji dalyvauti naujo pasaulio kūrimo procese „čia ir dabar“, o pedagogas ugdydamas tai gali iprasminti, sudaręs sąlygas vaikams panaudoti savo skirtingą sukauptą patirtị, kaip subkultūros dalį suaugusiujų pasaulio kultūroje.

\section{Vaikų lygybès ir individualios raiškos sampratų pedagoginės rekonstrukcijos}

Sąvoka lygybe visos vaiko individualybės raiškos įvairovès ugdyme neapibrèžia, atskleidžia tik tam tikrą požiūrị i vaikus, kaip skirtingus ir individualius. Kartu ji ipareigoja pedagogus vertinti vaikus tam tikrose situacijose kaip tapačius, panašius (dèl vaikystės periodo bruožų raiškos), taip pat kaip skirtingus ir individualius. Laikantis lygybės principo, E. Frede (1995) teigimu, interpretuojamos ne visos vaikų ugdymo situacijos, kuriose reiškiasi jų individualybè, bet atkreipiamas dèmesys i šiuos klausimus: „Ar ji tapo ugdymo vertybe (tèvams ir pedagogams)?“ ir „Ar jos paisymas yra reikšmingas tėvams ar pedagogams?“, „Ar ji yra kvestionuojama kaip ugdymo pasiekimas, ar kaip sallyga, trukdanti pedagogams formuoti bendrumą tarp vaikų, kaip besimokančiujų?" Frede (1995, p. 78).

Šiuolaikiniam pedagogui būtina ịvaldyti „naujaji“ žinojimą, ịveikti vaikų individualios raiškos vertinimo stereotipus ir suvokti žinių apie vaikų individualybę daugiafunkciškumą bei rekonstrukcini pobūdị. Pedagogas turi suvokti vaikų lygybès idejjas, pagristas sugestyvaus egitalitarizmo samprata ir iš esmès atstovaujančias ugdyme radikaliajam pliuralizmui.

M. Wimmer klausia: „Ar pasiseks šią idèją igyvendinti, jeigu šiuolaikiniame ugdyme egzistuoja nelygybė tarp dvieju grupiu - vaikų ir suaugusiujų, tačiau ši situacija suvokiama ne kaip socialinès nelygybès rūšis?" (Wimmer, 1998, S. 18). O. Hansmann, W. Marotzki požiūriu, vaikų lygybès situacija priklauso būtent nuo to, „kaip pedagogas suvokia vaikų lygybės ir nelygybės situacijas ugdyme, vaikų nelygybès situaciją priskiria „normaliai“ ar „nenormaliai“, kartu ir koreguotinai“ (1993, p. 91). Tačiau, M. Wimmer teigimu, vaikų lygybè visų pirma turi būti igyvendinta vaikams ir suaugusiesiems sąveikaujant, kad vaikų individuali raiška taptų ugdymo vertybe (1998, S. 18). Tokị vaikų lygybès suvokimą iprasmina idejja: vaikų individualūs skirtumai reiškiasi jiems būnant bendraamžių grupejje, nes čia susiklosto sąlygos vaikams suvokti ne tik skirtumus, bet ir tarpusavio panašumus.

Vaikų lygybès samprata skatina formuotis pliuralistini požiūrị i vaikų mokymo(si) i̇vairovę, suvokiant individualius jų skirtumus, kaip ugdymo vertybę, 
kartu atmetant siekį formuoti dirbtinį bendrumą tarp vaikų. Esant tokiam ugdymui, E. King (1996) nuomone, pedagogas gali ịprasminti save kaip individualybę (mąstydamas, veikdamas, priimdamas sprendimus).

U. Preuss-Lausitz (1993) pateikia tokias pagrindines ugdymo, pagristo vaiku lygybės samprata, vertybes: atsakomybė ir pagarba žmogaus prigimčiai, tolerancijos priešpriešinimas nepagarbai, konfliktinis ugdymas vietoj įtampos ir konfliktu, orientavimasis į pedagogo socialinę atsakomybę už naujos ir socialiai visavertės žmoniu kartos ugdymą vaikysteje. Vaikų lygybès interpretavimas sugestyvaus egalitarizmo pagrindu padeda atsakyti į tradicinį pedagoginị klausimą: „Ką reiškia „kitoks“ vaikas?“ (Marcon, 1990, p. 59). „Kitokio“ vaiko sampratai, A. Prengel (1997, 1998) teigimu, suteikiamas naujas turinys, kartu skatinama keisti pedagogų požiūrị i ugdymą, kaip individualią vaikų raiškos sriti. Ugdymo tikslu tampa klausimai: „Ar vaikas yra išsiugdę siekị būti kitokiu?“, „Ar yra save suvokęs ir priëmęs, būdamas „kitokiu“?“, „Ar nepasmerkè savęs dèl individualių skirtumų?“, „Ar vaikai nèra praradę savojo „Aš“‘?“. U. Preuss-Lausitz (1993) nuomone, tai vieni svarbiausių ugdymo, nukreipto ị skirtingų vaikų lygiavertiškumą, klausimai, kurių atsakymų pagrindu atsiranda supratimas: „Ką reiškia vaikui vaikystejje užimti lygiavertę, o ne hierarchinės priklausomybės nuo suaugusiujų poziciją?“ Tai skatina pedagogus ugdymą vaikystėje suvokti ne tik kaip situacini, bet ir kaip ,ilgalaiki vaikų socialinès raidos projektą" (Rabe-Kleberg, 1991, S. 72). Juo siekiama atsisakyti ugdymo, iprasminančio „nelygybę visiems vaikams“, kuris yra grindžiamas vaikų individualumo asimiliacija ir jų išskirtinumo konsekvencija.

\section{Ugdymas kaip vaikų ir suaugusiųjų dialogo prasminis-situacinis kontekstas}

Ugdymo, kaip dialogo, samprata yra alternatyva tradicinio ugdymo suvokimui, kurio pagrindą sudaro pedagoginis monologas, kai „kalbantysis ir tylintysis yra vienas ir tas pats“ (Gobel, 1981, S. 94). Ugdymas, kaip dialogas, šią sampratą paneigia ir santykius tarp vaikų bei pedagogų grindžia lygiaverte partneryste, susikalbejimu, kai iniciatyvos tiek „klausiantiesiems“ tiek ir „kalbantiesiems“ yra abipusiai reikšmingos bei skatina susikalbejjimo procesus. Pedagogų ir vaiku patyrimas vertinamas kaip lygiaverčiai reikšmingas ugdymą plètojant pasitelkus dialoga, kuris jiems reiškia ir „bendro“ su suaugusiaisiais socialinio projekto rašymą ,čia ir dabar“. Kartu ugdymas, pasitelkus dialogą, padeda spręsti svarbiausius socialinius uždavinius mikroaplinkoje, pratinantis juos spręsti per skirtingą patirti 
turinčių žmonių, suaugusių ir vaikų, sąveiką, mokantis jiems ,,solidarizuotis sprendžiant bendražmogiškas problemas“" (Freire, 1997, S. 108).

\section{Ugdymas kaip dialogas}

Ugdymas, kaip dialogas, plètojamas realiose vaiko gyvenimo ir tarpusavio sąveikos situacijose, sąveikos „vaikai-vaikai“ reikšmes kontekstualizuojant ir jas atskleidžiant pasitelkus aprašomuosius diskursus (Hamburger, 1988; Kron, 1986; Gills, 1995), naratyvinius tekstus, korespondencijos pobūdžio pranešimus. Ypač dažnai taikomas diskursas, kuris suvokiamas kaip ,išplètota kalba apie kokị nors dalyką pagal tam tikrą sistemą“ (Donskis, 1994, p. 15), kaip ,pasakojimas, turintis konkretų autorių, todèl pagrịstas konkrečia autorine patirtimi“" (Marshall, 1994, p. 40).

Taikydamas ugdomaji dialogą pedagogas išgyvena vaikams reikšmingų situacijų i̇vairovę ir savaime tampa netiesioginiu jų dalyviu bei partneriu. Išskirdamas vaikams svarbius socialinius-kognityvinius kontekstus, jis atranda idejų kurios svarbios ugdymo(-si) procesui, kai nuolat integruojama vaikų patirtis. Situaciniai, reikšminiai kontekstai ,išgrynina“ suaugusiujų pasaulio sąsajas su vaikais ir sudaro jiems galimybę ugdymą pagrissti tarpusavio susitarimo, konvencialumo principais. Tokiame ugdyme dažnai taikomas ir korespondencijos principas, „siunčiant vienas kitam pranešimus apie abipusiai reikšmingus dalykus“ (Prengel, 1998, S. 73), kuriuos dekodavus ugdymas suaugusiesiems ir vaikams tampa prasmingu procesu.

Korespondencijos būdas „vaikai $\rightarrow$ pedagogai“ sudaro vaikams galimybę pranešti pedagogams priimtinais būdais apie savo egzistavimą ir jiems svarbias sąlygas. Šiuos pranešimus dekoduojant, gali būti suvokiamos ugdymo, kaip dialogo „suaugusieji-vaikai“ plètojimo(si), ypatybès vaikams reikšmingos sąveikos „A š“„Tu“-,,Mes“" kontekste. Pateiksime šių kontekstų dekodavimo pavyzdžių.

Pedagogas, dekoduodamas vaikų tarpusavio sąveikos „A s““-,,Tu“-,,Mes“ situacinius kontekstus, ne tik geriau juos pažista, bet ir suvokia vaiką, kaip ugdymo subjektą bei dalyvị, savarankiškai gebanti kurti jam reikšmingą patyrimą. Vaiko(ų) individualybe pedagogui atsiskleidžia per neiprastas, mažai jam iki tol žinomas vaikų tarpusavio sąveikos situacijas, kurios yra natūraliai susiklosčiusios, todèl jose ryškejja vaiku gebejjimas savarankiškai praturtinti savo patirti, siekis išsiskirti iš kitu, lyginant save su kitais ir ieškant panašumo bei skirtumų. 


\section{1 lentele. Vaikams reikšmingų sąveikos „Aš-Tu-Mes“ pranešimų kontekstai} ir jų dekodavimas

\begin{tabular}{|c|c|c|c|c|c|}
\hline \multirow{2}{*}{$\begin{array}{l}\text { Eil. } \\
\text { Nr. }\end{array}$} & \multirow{2}{*}{$\begin{array}{c}\text { Vaikams } \\
\text { reikšminių } \\
\text { pranešimų } \\
\text { „Aš-Tu-Mes“ } \\
\text { kontekstai }\end{array}$} & \multirow{2}{*}{$\begin{array}{l}\text { Pranešime „užslèpta“ } \\
\text { informacija }\end{array}$} & \multicolumn{2}{|c|}{ Pranešimo dekodavimas } & \multirow{2}{*}{$\begin{array}{l}\text { Ugdymui, } \\
\text { kaip dialogui, } \\
\text { reikšmingos } \\
\text { idèjos }\end{array}$} \\
\hline & & & $\begin{array}{l}\text { Suaugusiujų } \\
\text { sampratų } \\
\text { reikšmėmis }\end{array}$ & $\begin{array}{l}\text { Vaikų sampratų } \\
\text { reikšmėmis }\end{array}$ & \\
\hline 1. & $\begin{array}{l}\text { Aš nesu Tu } \\
\text { ir aš Tave } \\
\text { nepakankamai } \\
\text { pažistu }\end{array}$ & $\begin{array}{l}\text { Vaikų domėjimasis } \\
\text { savimi ir vienas kitu } \\
\text { vyksta lyginant save } \\
\text { su kitais, prioriteta } \\
\text { teikiant ne „kitam“, o } \\
\text { sau, kaip išskirtiniam } \\
\text { asmeniui. } \\
\text { „Kitam“ deleguojamos } \\
\text { tik skiriamosios, o ne } \\
\text { panašios savybės. } \\
\text { Aš, kaip individualus, } \\
\text { suvokiamas } \\
\text { akcentuojant } \\
\text { skirtingumą su } \\
\text { „kitais“, kai „kitas“ } \\
\text { yra nepanašus i̇ „Aš“, } \\
\text { todèl ir nepažistamas }\end{array}$ & \begin{tabular}{|l} 
Vaikai yra \\
egocentriški \\
ir nepakantūs \\
„kitiems“ \\
vaikams, \\
susipažinimas \\
su „kitais“ \\
vyksta \\
susipriešinimo, \\
o ne bendrumo \\
pagrindu
\end{tabular} & $\begin{array}{l}\text { Vaikai siekia } \\
\text { individualios } \\
\text { saviraiškos, } \\
\text { „Aš““ jiems dar } \\
\text { nepakankamai } \\
\text { pažistamas, } \\
\text { tačiau vaikai, } \\
\text { save išskirdami } \\
\text { iš kitu, nori } \\
\text { susipažinti ir } \\
\text { su kitais, save } \\
\text { suvokdami } \\
\text { kaip nepanašų i } \\
\text { kitus, o „kitus““ } \\
\text { vertindami kaip } \\
\text { nepažintą „Aš““ }\end{array}$ & $\begin{array}{l}\text { Vaikai, skirtingai } \\
\text { nei suaugusieji, } \\
\text { vertina „Aš“ ir } \\
\text { „kita“, labiau } \\
\text { toleruodami } \\
\text { skiriamąsias } \\
\text { „Aš““ ir „Tu“ } \\
\text { ypatybes. } \\
\text { Vaiko savigarba } \\
\text { yra kaip } \\
\text { pagrindas jo } \\
\text { individualiai } \\
\text { raiškai } \\
\text { sąveikaujant su } \\
\text { kitais }\end{array}$ \\
\hline 2. & $\begin{array}{l}\text { Mes visi } \\
\text { esame ne tik } \\
\text { skirtingi, bet } \\
\text { ir reiškiamés } \\
\text { kaip unikalūs, } \\
\text { kuriame } \\
\text { savaja } \\
\text { gyvenimo } \\
\text { istorija, } \\
\text { tačiau kartu } \\
\text { mes esame } \\
\text { ir panašūs } \\
\text { - mokomés, } \\
\text { žaidžiame, } \\
\text { domimés vieni } \\
\text { kitais }\end{array}$ & $\begin{array}{l}\text { Siekis išsiskirti iš } \\
\text { kitų, priskiriant sau } \\
\text { unikalius bruožus, } \\
\text { ir jị lydintis noras } \\
\text { būti panašiu i kitus, } \\
\text { jausti su kitais } \\
\text { bendrumą. Bendrumas } \\
\text { suvokiamas priskiriant } \\
\text { visiems bendrus } \\
\text { siekius ir veiklą }\end{array}$ & $\begin{array}{l}\text { Vaikai yra } \\
\text { egocentriški ir } \\
\text { nori atkreipti } \\
\text { i save dėmesị. } \\
\text { Vaikystėje } \\
\text { vaikai yra } \\
\text { panašūs } \\
\text { vienas į kita, } \\
\text { nes panaši } \\
\text { ir jų veikla: } \\
\text { jie mokosi, } \\
\text { žaidžia, } \\
\text { domisi vieni } \\
\text { kitais, todèl be } \\
\text { suaugusiujų } \\
\text { pagalbos } \\
\text { nesugeba } \\
\text { prasmingai } \\
\text { gyventi ir } \\
\text { dažnai užsiima } \\
\text { beprasmiška } \\
\text { veikla }\end{array}$ & $\begin{array}{l}\text { Vaikai yra } \\
\text { skirtingi ir } \\
\text { pabrěžia savo } \\
\text { asmeninio } \\
\text { (individualaus) } \\
\text { gyvenimo } \\
\text { skirtinguma, } \\
\text { kartu ir } \\
\text { bendrumo su } \\
\text { kitais istoriją }\end{array}$ & $\begin{array}{l}\text { Vaikų } \\
\text { individualybės } \\
\text { raiška vyksta ne } \\
\text { tik akcentuojant } \\
\text { jų unikalumą, } \\
\text { bet ir panašumą } \\
\text { su kitais, } \\
\text { suvokiant } \\
\text { bendras visiems } \\
\text { vaikams veiklos } \\
\text { rūšis. } \\
\text { Vaikai patys } \\
\text { kuria savo } \\
\text { gyvenimo } \\
\text { istorija, yra ir } \\
\text { jos autoriai, ir } \\
\text { dalyviai }\end{array}$ \\
\hline
\end{tabular}


Priimant vaiką, kaip individualią asmenybę, susidaro sąlygos puoselèti tikraji bendruma, kurio pagrinda, E. Frede (1995) nuomone, sudaro pedagogo supratimas, kad „kiekvienas vaikas nori reikštis skirtingu būdu, kartu siekia apie tai pranešti kitiems ir sužinoti, ką apie tai mano, jis nori suprasti, kas kitiems svarbu“ (1995, p. 32). Vaikų dėmesys vienas kitam yra ir jų natūraliai vienas kitam teikiama savitarpio pagalba, kurios pažinimas pedagogui yra reikšmingas, siekiant suprasti pati svarbiausią aplinkos subjektą - vaiką, kaip individualybę. U. Preuss-Lausitz nuomone, šiose tarpusavio situacijose savaime plettojasi ir vaiku ,mokymosi vieni iš kitų“ būdai - tai „,ne tik patyrimo perèmimas, bet ir vienas kito pažinimas“ (1993, p. 75). Pedagogas tokioje ugdymo taikant dialogą atmosferoje yra vaiko socialinio tapsmo dalyvis, ,galintis rūpintis ir savo socialiniu bei kultūiniu tobulèjimu“. K. Klemm (1987) šiuos teiginius papildo naujais argumentais: ugdymo situacijose pasitelkęs dialogą pedagogas kiekvieną kartą praturtejja žmogaus, kaip individualybès, patirtimi, i Ł ši pažinimo procesą ji itraukia patys vaikai, ị kuriuos žvelgiama kaip į individualius ir skirtingus.

\section{Išvados}

1. Pedagogas, kurdamas naujaji žinojimą (angl. new knowledge), gali remtis vaikų lygybès ir ugdymo dialogo sampratomis, lygybę suvokdamas ne tik kaip prielaidą būti panašiu į kitus, bet ir kaip būtiną sąlygą vaikų ankstyvojo individualumo raiškai. Individualizuoto ugdymo rekonstrukcijos gali vykti stebint, fiksuojant ir išskiriant vaikų „pranešimus“, siunčiamus suaugusiesiems iš vaikų subkultūros, kurie pedagogo turi būti suvokiami kaip individualizuoto ugdymo diskursas ir pedagoginiu rekonstrukcijų metakontekstai.

2. Siūloma tokia pedagoginių pažiūrų i vaikų sąveikos („A š“, „Tu“, „Mes“) rekonstrukcijų kryptis: orientacija i ,,užslèptas“ vaikų natūralios socialinės sąveikos reikšmes, kurių pagrindas - skirtybių ir bendrybių su suaugusiaisiais suvokimas, nes vaikai ir suaugusieji yra ne tik skirtingi, bet ir panašūs, nes kurdami savają gyvenimo istoriją jie reiškiasi kaip nepakartojami individai.

3. Rekonstruojant pažiūras i vaikus kaip skirtingus ir visaverčius socialinius individus, pedagogams tenka ịveikti išankstines nuostatas dèl vaikų tarpusavio santykių, esamą diskriminaciją, kaip būtiną elementą suaugusiujų neprižiūrimoje aplinkoje. Pedagogams trukdo ir neargumentuotos nuostatos dèl vaikų subkultūroje vyraujančio siekio būti panašiais vie- 
Audronė Juodaitytė

\section{nas i kita, o ne individualiais. Iveikus šias nuostatas, pedagogams svar- bios tampa vaiku pasaulio reikšmės: jau ankstyvoje vaikystèje vaikai siekia individualios saviraiškos, kartu - asmeninio pedagogo dèmesio.}

Gauta 20131001

Pasirašyta spaudai 20140214

\section{Literatūra}

Caldwell, B. M. (1990). Educare: A new professional identity. Dimensions of Early Childhood. Cambridge: Harward University Press.

Donskis, S. (1994). Moderniosios sq̨monès konfiguracijos. Kultūra tarp mito ir diskurso. Vilnius.

Fetscher, I. (1983). Neokonservative und "Neue Rechte”. Der Angriff gegen Sozialstaat und liberale Demokratie in den Vereingten Staaten, Westeuropa und der Bundesrepublik. München.

Feuser, G. (1992). Integration die gemeinsame Tätigkeit (Spielen. Lernen. Arbeit). Behindertenpädagogik, Bd. 2: 85-105.

Frede, E. (1995). Child discourse. New York: Academic Press.

Freire, P. (1997). Pädagogik der Unterdrückten. Bildung als Praxis der Freiheit. Hamburg.

Gills, J. (1995). Children Playing and Children Doing Philosophy: Why are they Both So Interesting? Thinking in Education, vol. 12, no. 3: 2-27.

Göbel, R. (1981). Verschiedenheit und gemeinsames Lernen. Königsstein.

Hansen, A., Kaufmann, K., Saifer, S. (1997). Ugdymas ir demokratijos kultūra. Ikimokyklinis amžius. Lietus.

Hansmann, O., Morotzki, W. (1993). Diskurs Bildungstheory. Weinheim und Basel.

King, E. J. (1996). Education and Social Change. Oxford: Pergamon Press.

Klemm, K. (1987). Bildungsexpansion und ökonomische Krise. Zeitschrift für Pädagogik, Bd. 6, S. 114-122.

Kron, M. (1986). Integration des Prozess. Sonderpädagogik, Bd. 3-4: 115-162.

Marcon, R. (1990). Early Learning and Early Identification: Final Report of the Three Year Longitudinal Study. Washington, D.C.: Eric Reproduction Service.

Marshall, H. H. (1994). Children's understanding of academic tasks: Work, Play, of Learning. Journal of Research in Childhood Education, vol. 9: 35-49.

Prengel, A. (1997). Schulbildung und Gleichberichtingung. Frankfurt.

Prengel, A. (1998). Zur Dialektik von Gleichheit und Differenz in der Integrations-pädagogik. In: H. Eberwein. Behinderte und Nichtbehinderte lernen gemeinsam, Handbuch der Integrationspädagogik, Weinheim und Basel, p. 70-79.

Prengel, A. (1998). Zur Dialektik von Gleichheit und Differenz in der Integrations-pädagogik. In: H. Eberwein. Behinderte und Nichtbehinderte lernen gemeinsam, Handbuch der Integrationspädagogik. Weinheim und Basel, p. 70-79.

Preuss-Lausitz, U. (1993). Die Kinder des Jahrhunderts. Zur Padagogik der Vielfalt im Jahr 2000. Weinheim und Basel.

Rabe-Kleberg, U. (1991). Modernisierung von Kindheit? Order Zur Rolle von Schule, Sozialpädagogik und Schulsozialarbeit bei der Veränderung von Kindheit in den letzten zehn Jahren. Bielefeld.

Wimmer, M. (1998). Die Kindheit auf dem Lande. Reinbek. 


\section{PEDAGOGICAL RECONSTRUCTIONS OF CHILDREN'S INDIVIDUALISED EDUCATION: DISCOURSES AND METACONTEXTS}

\section{Audronė Juodaitytė}

Summary

The article discloses main types of children's interaction ("I", "You", "We") and its meanings, emerging in natural environment as well as the type of pedagogical reconstructions, corresponding or not corresponding to these meanings. Using the method of conventionality and correspondence, it is orientated to the idea of respective education, defending the right of the child as a person and individual to remain unique in education. It is demonstrated how the educator can give a sense to this children's opportunity, constantly communicating with the children's world, interpreting education on the basis of suggestive egalitarianism ideas and implementing it as a child-adult dialogue.

Almost all pedagogy of the 20th century is grounded on "vulgar inequality" or "children's perverse equality" conceptions, which are grounded on the distinctive approach to children as "to different". This was the basis for consolidation of inequality in education processes.

Children's modern individualised education is grounded on the conception of children's equality and on the thesis of suggestive egalitarianism. It radically changes traditional education, which is dominated by devaluation of different and individual children and which gratuitously prioritises certain features and gratuitously devaluates others. This determines transition to education, in which children's individual differences and their exceptionality are like values of education.

However, individualising education, teachers have to acquire a new approach to manifestation of children's individuality and exceptionality in education processes and learn to cognise the child as an individual constructing his/her own experience. Therefore, the research problem arises: How, in what ways and where can the educator acquire new experience and conceptions, necessary for individualisation of children's education and how can he/she reconstruct this experience?

Modern pedagogical awareness is interpreted as moving from theory to practice, from generalised truths to concrete, practical ones. At the same time it is described as an attempt to cope with pure thinking (object oriented) truths and seek 
subjective spring, individual interaction with the children's world. In these conditions discovered truths are linked with the already existing pedagogical attitude to indefiniteness, localisation and monumentalisation of children's life situations. Alteration of new pedagogical attitudes to children's education takes place not only in the interaction with social environment as reality but also with the child's inner world as his/her nature and with his/her created environment as subculture.

Meanings of the children's world as social, subcultural space created by themselves, are disclosed through the contextual-situational pedagogical type polylogue with values of the children's world, going deep into it by means of reflection and making constructive type pedagogical insights. Possibilities of modifying pedagogical attitudes are searched for, constantly developing the educator's interaction with the meanings of the children's world. This helps to find ideas for projection of children's education, which is orientated to the educator's interpersonal interaction with the child.

The article highlights the most important ideas, connecting the educator's neopedocentristic attitudes into the education project, which is grounded on the idea that the children's world is like a part of the adults' world and that children have the right like adults to participate in the creation of the new world "here and now", while during the education process the educator can give a sense to this idea if he/ she creates conditions for different and individual children to use accumulated experience as a part of subculture in the culture of the adults' world.

The concept "equality" does not define the whole diversity of manifestation of the child's individuality in education; it only discloses a certain attitude to children as to different and individual. At the same time it commits educators to value children in certain situations as identical and similar (due to manifestation of childhood period features) and also as different and individual. Based on the principle of equality, according to Frede $(1995,1996)$, all education situations in which the child's individuality manifests itself are not interpreted but attention is paid to the following questions: "Has it become an educational value (for parents and educators)?" and "Is its observance significant for parents and educators?", "Is it questioned as an achievement of education or as a condition hindering educators to form commonality between children as learners?" (Frede, 1996, p. 78).

The modern educator has to master the "new" knowing, cope with stereotypes evaluating children's individual expression and perceive multi-functionality and reconstructive nature of knowledge about children's individuality. The educator must perceive the ideas of children's equality, grounded on the conception of suggestive egalitarianism and by their essence representing radical pluralism in education. 
The conception of education as a dialogue is an alternative for the perception of traditional education, which is based on the pedagogical monologue, when "people who speak and who are silent are one and the same thing" (Gobel, 1997, p. 94). Education as a dialogue negates this conception and grounds relations between children and educators on tantamount partnership, mutual understanding, when initiatives for both "listeners" and "speakers" are mutually significant and encourage speaking processes. Educators' and children's experience is valued as equally significant for (self-)development of education towards the dialogue, which for them at the same time means writing a "joint" social project with adults "here and now". At the same time dialogue education is directed to solving of the most important social tasks in microenvironment, accustoming to solve them by means of interaction between people, adults with different experience and children, who are learning to "identify themselves in solutions of general human problems" (Freire, 1997, p. 108).

During dialogue education the educator finds himself in the diversity of situations that are significant for children and naturally becomes their participant and partner, distinguishing social-cognitive contexts that are important for children, and finds ideas for (self-)development of education, constantly including children's experience into it. Situational, notional contexts "purify" links between the adults' world and children and create a possibility to ground education on "interpersonal agreement and conventionality principles". In such education the principle of correspondence is often applied too, "sending messages to each other about mutually significant matters" (Prengel, 1998, p. 73), decoding of which enables to make education meaningful for adults and children.

When children are tolerated as individuals, conditions for the formation of real commonness between them are created. According to Frede, its basis is the educator's conception that "every child wants to manifest himself/herself in a different way and at the same time wants to inform others and find out what others think about this as well as understand what is significant for others" (1996, p. 32). Children's attention to each other at the same time is also their natural mutual assistance to each other, cognising the most complex object of the environment - the child as an individuality. In Preuss-Lausitz's opinion, in these interpersonal situations ways of "learning from each other" are unconsciously developed, taking place "not only as taking over the experience but also as cognition of each other" (1993, p. 75). In such atmosphere of dialogue education the educator is like a participant of the child's social becoming, who at the same time "can also attend his own social and cultural development". Klem (1987) supplements these statements with new arguments: in the situations of dialogue education the educator is every time 
enriched with human life plans, into which he/she is involved by the very children, arousing attention to them as individual and different (1987).

Constructing "new" thinking, the educator can ground it on the concepts of the dialogue on children's equality and education, perceiving equality not only as a precondition to be similar to others but also as a prerequisite for manifestation of children's early individualism. Reconstructions of individualised education can take place while observing, recording and distinguishing children's "messages", sent to adults from children's subculture, which have to be perceived by the educator as a discourse on individualised education and as metacontexts for pedagogical reconstructions.

The following trend of reconstructions of pedagogical approaches to children's interaction ("I", "You", "We") are proposed: orientation to "hidden" meanings of children's natural social interaction, which are based on the perception of differences and commonalities with adults because children and adults are both different and similar due to their manifestation as unique individuals in the creation of their life story.

Key words: children's individualism, discourses, metacontext. 